\title{
DIALYSIS ACTIVITY OF THE HEMODIALYSIS (HD) CENTER AT UNIVERSITY HOSPITAL OLOMOUC IN THE PAST DECADE
}

\author{
Jana Zahálková
}

$3^{\text {rd }}$ Clinic of Internal medicine, University Hospital Olomouc

Received: September 21, 2002

Key words: Blood purification / Dialysis activity / Patient structure / Mortality

The paper presents a summary of dialysis statistics at the Olomouc Hemodialysis Center during the period 1991-2001. The number of individual treatments, patient structure, mortality and survival of patients on dialysis are featured, along with a comparison of state norms in some instances.

\section{DIALYSIS CAPACITY}

The Hemodialysis Center (HDC) at 3rd Medical Clinic of University Hospital Olomouc is the fourth oldest such center in the Czech Republic (the first hemodialysis treatment was carried out in 1964) and for many years it has provided a stable treatment basis for those suffering from kidney failure in the North Moravian region. In the past decade the activity at HDC has been influenced by the changes which have taken place over the entire Czech Republic. The health care situation after 1989 enabled the start of liquidating the great debt which our society owed towards patients with terminal kidney failure. Due to low dialysis activity, in 1989 our country placed at number 24 of the 32 countries listed in the European Dialysis and Transplant Association (EDTA) register ${ }^{1}$. In the years following, the capacity of dialysis treatment grew such that new HDCs were founded and the existing centers were expanded. Both the number of blood purification treatments and the number of patients treated grew (Fig. 1) (ref. ${ }^{2}$ ).

Even the establishment of new centers in the area around Olomouc, such as the HDCs in Jeseník, Bruntál, Vsetín, Prostějov and Šumperk, could not properly service the influx of new patients. For this reason, in 1995 the capacity of the Olomouc center regarding dialysis beds was expanded to the current 16 . The prevalence of dialysis patients in the Olomouc catchment area thus rose from the figure of 91 patients per 1 million inhabitants in 1991 to the current $304 \mathrm{ppm}$, which is approaching the current national average of 379 ppm (Fig. 2).

\section{IMPROVING THE QUALITY OF TREATMENT}

The majority of treatments carried out in our faculty are comprised of standard hemodialysis through the use of low-flux dialysis membranes. The number of hemodialysis treatments carried out in 2001 represented an increase of 55\% over the amount carried out in 1991. In 1993 we started to use synthetic high-flux membranes, which made possible the use of filtration techniques, initially in the form of low volume hemodiafiltration. From 1996, after further equipment upgrades, we began to carry out high volume on-line hemofiltration (HF) and hemodiafiltration (HDF) (Fig. 3). For a certain group of patients, for which it is necessary to attain more effective elimination of uremic toxins - patients with dialysis amyloidosis, problematic uremic neuropathy and osteopathy - we can thus provide higher quality methods of blood purification. The establishment of blood volume monitoring during dialysis and the determination of dialysis doses during the course of hemodialysis since 2001 have both contributed to the better cardiovascular stability and better metabolic compensation of our patients.

\section{OTHER ELIMINATION METHODS}

The number of hemoperfusions (the first such treatment in our HDC was carried out in 1984) and membrane plasmapheresis (in 1986) carried out has basically unchanged (Fig. 4). So too the indications for their use. Hemoperfusion is most often carried out due to intoxication by medicines or mushroom ingestion. The most frequent indications for the use of plasmapheresis have been thrombotic thrombocytopenic purpura, subacute glomerulonephritis, polyradiculoneuritis, myasthenia gravis and multiple myeloma with hyperviscosity syndrome. 


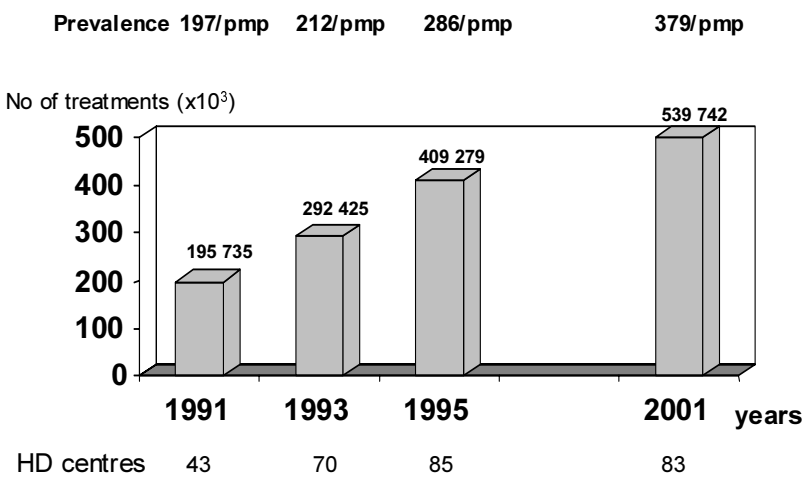

Fig. 1. The number of treatments (all methods of blood purification) in the Czech Republic between the years 1991 and 2001. The development of hemodialysis (HD) centers in the Czech Republic.

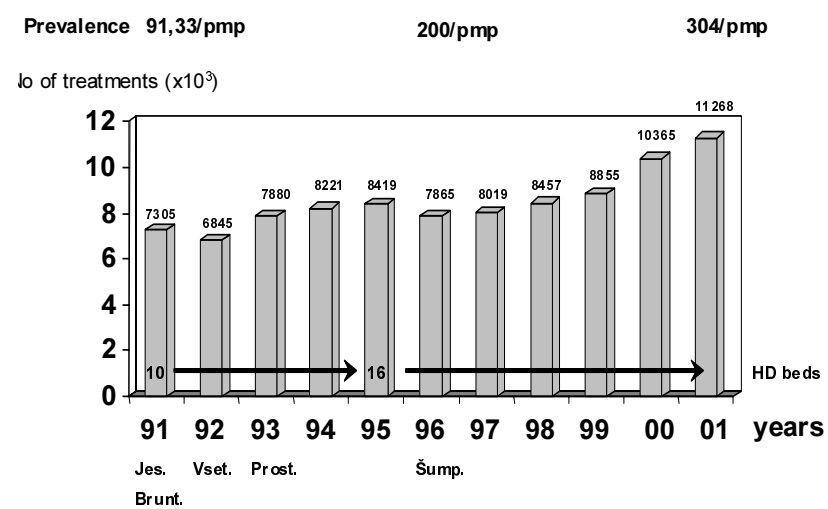

Fig. 2. The number of treatments (all methods of blood purification) and rising prevalence at the Olomouc HD Center between the years 1991 and 2001. The development of new HD centers around Olomouc.

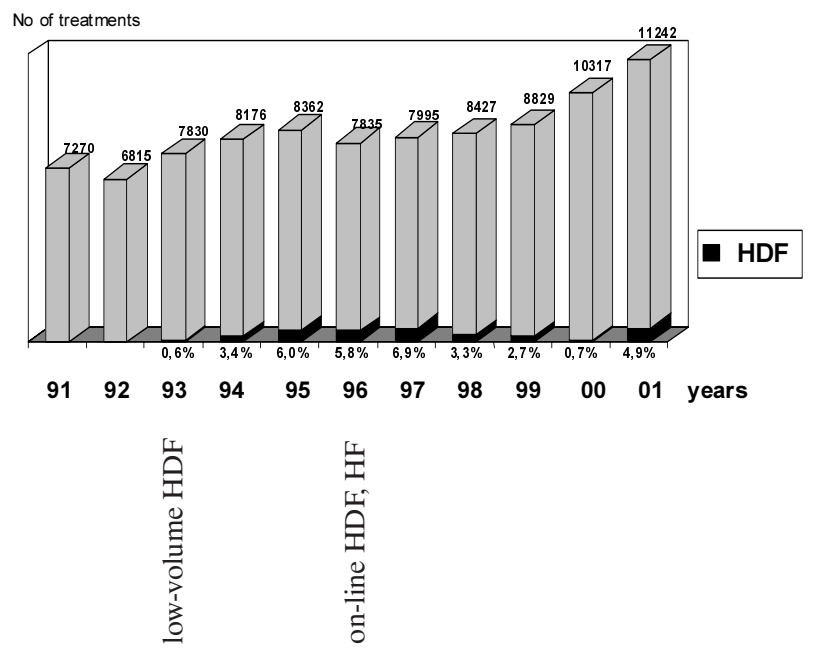

Fig. 3. The number of low-flux and high-flux dialysis at the Olomouc HD Center between the years 1991 and 2001.

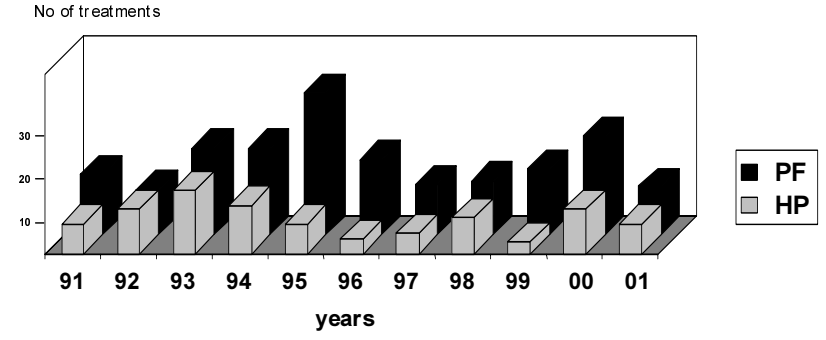

Fig. 4. The number of hemoperfusions (HP) and membrane plasmaferesis (PF) at the Olomouc HD Center between the years 1991 and 2001.

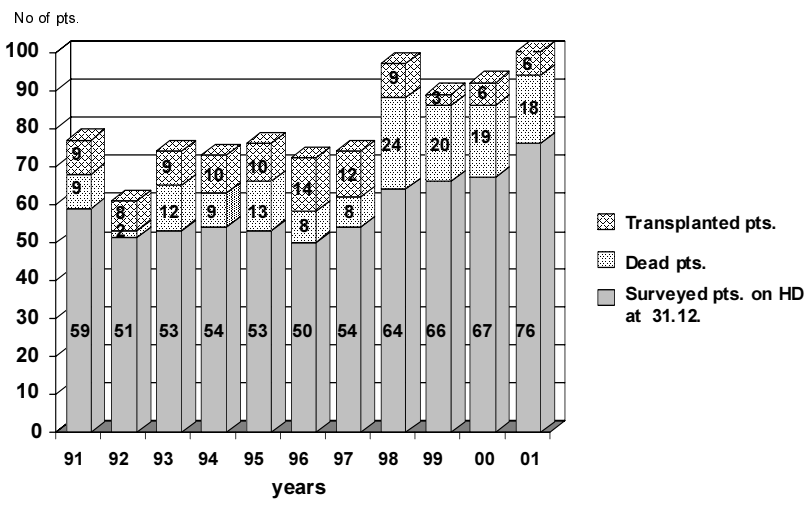

Fig. 5. The proportion of patients (pts) surveyed on dialysis at the end of every year and the proportion of dead and transplanted pts at the Olomouc HD Center between the years 1991 and 2001.

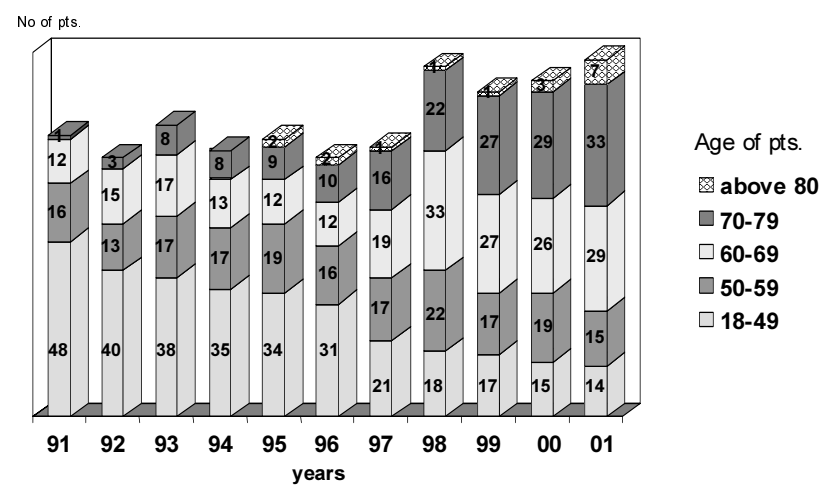

Fig. 6. Age distribution in dialysis pts between the years 1991 and 2001 at the Olomouc HD Center.

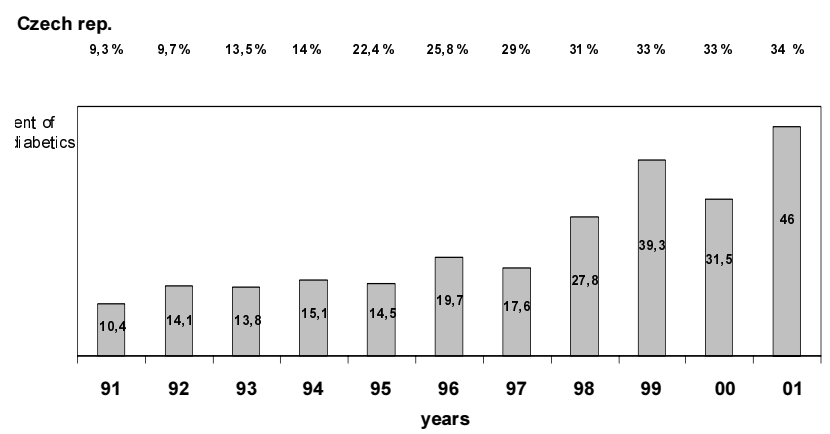

Fig. 7. The number of dialysis diabetics (expressed in percent of pts) at the Olomouc HD Center in comparison with percent of dialysis diabetics in the Czech Republic. 


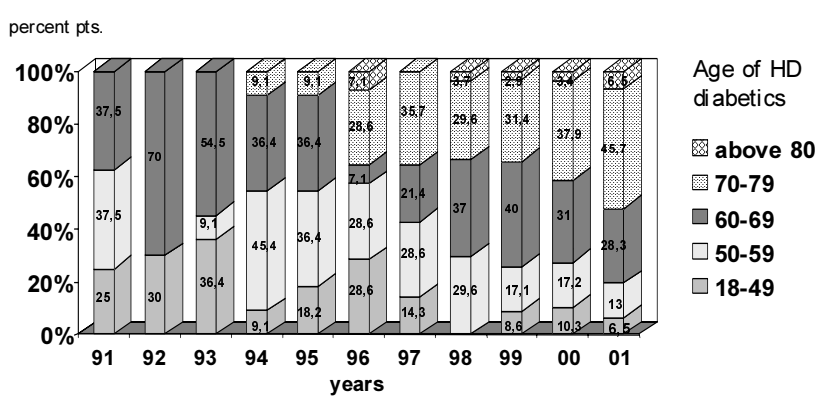

Fig. 8. Age distribution in dialysis diabetics. (Olomouc HD Center)

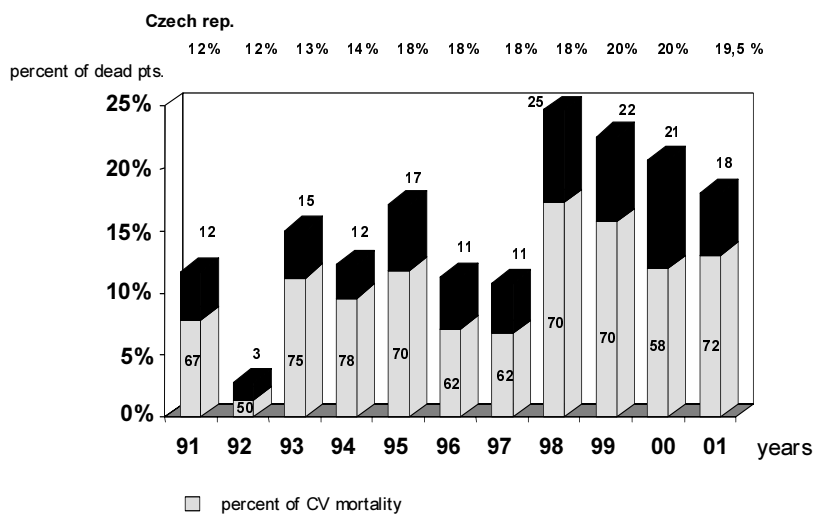

Fig. 9. Total mortality of Olomouc HD pts in comparison with total mortality of Czech HD population. Proportion of cardiovascu$\operatorname{lar}(\mathrm{CV})$ mortality at the Olomouc HD Center.

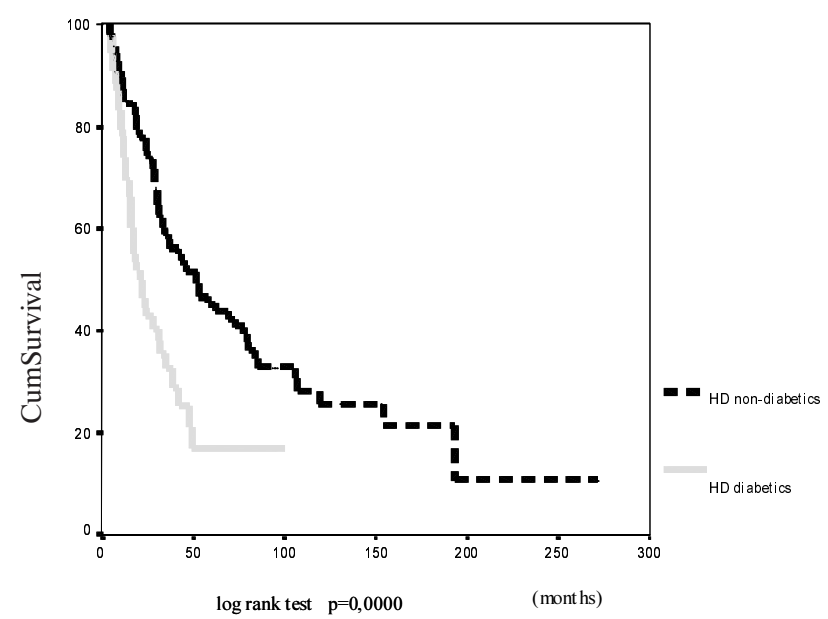

Fig. 10. Cumulative survival of Olomouc dialysis diabetics in comparison with survival of dialysis non-diabetics.

\section{PATIENT STRUCTURE}

The numbers of dialysis patients in individual years and their changes are broken down in Figure 5. The number of individual hemodialysis patients has increased because the number of patients with kidney failure due to diabetic nephropathy has increased. Owing imbalance in the number of transplantation candidates versus the availability of acceptable organs, and a growth in the number of patients with medical contraindications, the number of transplants has decreased. The overall number of patient fatalities has increased while at the same time the survival rate of patients has risen each year. Today hemodialysis treatment is available to any person who is in need of it.

The patient structure in the last ten years has changed considerably. In conjunction with worldwide and national trends, dialysis patients of advanced age have increased in number and the percentage of dialysis diabetics of that age has also grown considerably. The largest of these groups of elderly, more than $75 \%$ of diabetics in 2001, were 60 and older (Figs. 6, 7, 8).

\section{SURVIVAL OF DIALYSIS PATIENTS}

The age of patients is increasing and the ever-increasing growth of elderly diabetics in the dialysis population has brought with it increased complications and this has affected the long-term results of treatment. To a certain extent, due to average statistical values, they have distorted the picture of the length of the life of patients on dialysis. The polymorbidity of patients is growing and the high mortality rate of patients is connected with this. It is a general trend, perceivable both in the Czech Republic and in our HDC (Fig. 9). The big jump in the mortality rate in 1998 as opposed to 1997 was due to a $31 \%$ increase in patients logged in and at the same time a marked change in the composition of dialysis patients. There was an increase in the number of invalid patients and uremics with grave vascular complications.

In the consequence of the presence of multipleorgan handicapped, the most striking difference is in the length of survival on hemodialysis between diabetics and non-diabetics. The survival rate for dialysis diabetics is one-half. The survival rate after three years of dialysis at our HDC for non-diabetics is $60 \%$, vs. $35 \%$ for dialysis diabetics. Results after five years are even worse: $47 \%$ for non-diabetics vs. $18 \%$ for diabetics (Fig. 10).

Causes in mortality of dialysis patients worldwide have for many years been unchanged ${ }^{3,4}$. For several decades now, more than half of all such deaths have been due to cardiovascular causes, primarily heart failure, coronary disease, valvular disease and cerebrovascular attacks ${ }^{5,6}$. Despite an increase in factors which ought to unfavorably influence the number of cardiovascular attacks, the percentage of this mortality factor in overall mortality has not increased (Fig. 9). The reason for this is most likely the availability of effective 
medications (ACE inhibitors, epoetin, vitamin D) and the use of quality dialysis and monitoring technologies which can retard the process of vascular and heart complications.

The still high percentage of cumulative mortality in dialysis creates serious infection. In our HDC we have at present $10 \%$ of patients with necrotic ischemic defects in their lower extremities, which dramatically increase the risk of septic state. In recent years even the occurrence of neoplasms has clearly risen and their incidence in the dialysis program has generally increased. Ten percent of our dialysis patients suffer simultaneous malignity after inclusion into dialysis treatment.

Difficult situations have arisen not only for the patients themselves; their care has also become more difficult for all Center personnel. This concerns not only patients' blood purification, but patients' stay, which requires complex approaches and interdepartmental cooperation. Quite often intensive care and precise monitoring are necessary; at other times difficult-tosolve social problems again stand in the foreground.

\section{CONCLUSIONS}

1. Since 1996, when the establishment of dialysis regions in North Moravia was completed for the time being, the number of elimination methods carried out at the Olomouc HDC has increased. The largest increase took place in 2000 and 2001, when the yearly increase reached $17 \%$ and $9 \%$ respectively. Standard hemodialysis made up the majority of treatments, carried out 55\% more in 2001 than in 1991.

2. Apart from the quantitative indices, there was also a change in the quality of treatment. Since 1993 HDF and HF filtration techniques have been carried out in our facility, enabling more effective blood purification for patients. Thanks to other equipment in the Center it is possible to forego circulatory instability of patients during and after dialysis.

3. Trends in the number of hemoperfusion and plasmapheresis carried out in the last ten years are sustained. The indications for these treatments are basically unchanged.

4. The dialysis population is aging, the number of elderly patients is increasing. In $200140 \%$ of patients at the Olomouc HDC were 70 and older.

Since 1998 the percentage of dialysis diabetics has increased, making up one third of the patients in Olomouc; in 2001 almost one half of all patients were in the chronic dialysis program. More than $75 \%$ of diabetics were 60 and older last year.

5. The result of these trends in the makeup of patients is the high overall mortality rate exhibited most markedly in our HDS over the past four years (18-25\%). The survival rate of dialysis diabetics, due to their polymorbidity and advanced age, is half of that versus non-diabetics in our dialysis program.

\section{REFERENCES}

1. US Renal Data System: USRDS 1989 Annual Data Report. The National Institutes of Health, National Institute of Diabetes and Digestive and Kidney Diseases, Bethesda MD, 1998.

2. Lachmanová J (1991-2001) Statistické ročenky dialyzační léčby v České republice.

3. Fernández JM, Carbonell ME, Mazrudi N (1992) Simultaneuous analysis of morbidity and mortality factors in chronic hemodialysis patients. Kidney Int, 41, 1029-1034.

4. Locatelli F, Del Vecchio L, Manzoni C (1998) Morbidity and mortality on maintenance haemodialysis. Nephron, 80, 380-400.

5. Khan IH, MacLeod AM (1995) Identifying the high-risk dialysis patients: what are the benefits? Nephrol Dial Transplant, 12, 2176-2178.

6. Lazarus EG, Lowrie EG, Hampers CL (1975) Cardiovascular disease in uremic patients on hemodialysis Kidney Int, Suppl 7, S167-S175. 